\title{
Who Will Be the History Writers of the COVID-19 Pandemic?
}

\author{
Ruth Bishop, MBA@, Vy T. Tran Plata, MS, and Sarah M. Jabour, BA
}

University of Michigan Medical School, 1301 Catherine St, Ann Arbor, MI, USA.

J Gen Intern Med 37(6):1540-1 DOI: $10.1007 / \mathrm{s} 11606-022-07392-\mathrm{w}$

(C) The Author(s), under exclusive licence to Society of General Internal Medicine 2022

"S tories humanize us. They emphasize our differences in ways that can ultimately bring us closer together. They allow us to see how the world looks from behind someone else's spectacles. They challenge us to wipe off our own lenses and ask, 'Could I have been overlooking something all along?"' -R. Delgado, 1989.

This winter marks our two-year anniversary of life during the COVID-19 pandemic. As we reflect on our COVID-19 stories, images of "frontline workers" may easily come to mind: nurses, physicians, and other healthcare workers. These narratives were the dominant stories shared. These stories are valuable and need to be told, yet we worry about those that are persistently missing from the front pages of major newspapers, news outlets, and medical journals.

Where are the stories from bus drivers, grocery clerks, or hospital environmental service workers - the unsung heroes on the frontline? We may hear snippets or occasional accounts; however, these stories are far too often eclipsed by the other reigning stories of this time. Where are the stories from patients and marginalized communities? How can we preserve the stories of those disproportionately affected by COVID-19? How can we elevate the voices that have long gone underrepresented in medicine and society at-large?

Therefore, we pose the question - who will be the writers of the history of the COVID-19 pandemic?

Social scientists and critical race scholars have long referred to stories from oppressed or marginalized groups as "counterstories," stories which defy the ideologies or stereotyping of the dominant group. These stories shed light on the dominant group's blind spots and the ways that institutions benefit some at the expense of others or fail to consider them entirely ${ }^{1,2}$. People from oppressed communities have always told stories as a means to their own survival and liberation. There are numerous examples of how Black slaves or Native Americans composed songs and stories recounting their experiences and

Received September 3, 2021

Accepted December 30, 2021

Published online January 28, 2022 pain $^{2}$. Sharing these stories among people with shared identities often led to emotional healing, promoted group solidarity and cohesion, and resulted in tangible change ${ }^{1,2}$.

Stories from diverse backgrounds and identities can spur advocacy and help inform the creation of more inclusive and equitable health policies and guidelines, especially since certain marginalized groups are inordinately affected by pandemics ${ }^{3}$. Additionally, these stories can help address the narratives that ascribe blame to the individual behaviors of people of color or low-income communities for increased disease incidence and spread, rather than institutionalized racism and other forms of oppression ${ }^{4,5}$. Simply, counter-stories can enable "the listener and teller to build a world richer than either could make alone ${ }^{2}$."

It is these "pandemic counter-stories" which we should seek to preserve and elevate. Yet, in sharing these stories, we must first acknowledge historical reasons why certain narratives have been intentionally left out or gone unrecognized. History reveals that White middle- and upper-class stories are the privileged norm, while stories from people of color or low socioeconomic groups are distorted or silenced ${ }^{1}$. Medical institutions have a long history of afflicting abuse, providing inadequate healthcare, or patronizing marginalized populations, including people experiencing homelessness, people with substance use disorders ${ }^{6}$, people who are incarcerated, and communities of color ${ }^{4,5,7}$. The status quo of structural racism and classicism upheld within society is also ingrained within our healthcare system and academic medical centers ${ }^{4,5}$. If the institution of medicine seeks to be more inclusive of pandemic counter-stories, it will require intentional actions resisting these dominating exclusionary forces ${ }^{2}$.

What we argue is needed before a call for action is a call for reflection. To reimagine pandemic stories to be more inclusive of marginalized voices, we must first intentionally listen to these voices. To listen means to give attention to both the storyteller and their story. We argue that there is no paucity of pandemic counter-stories, merely a lack of attention highlighting them. Secondly, we must recognize that there are limitations to what physicians can contribute to the conversation of storytelling inclusivity. Social scientists and historians of race and medicine have long grappled with these issues ${ }^{7}$, providing decades of research and analysis of counter-stories as a way to shift the needle towards equity. Academic medicine should turn to these experts to generate new methods to "give voice and turn the margins into places of transformative resistance ${ }^{1}$." 
To conclude, counter-storytelling has the power to both humanize and help us construct a more just world. Academic medicine can counter its own history of marginalization of underrepresented groups' stories through intentional reflection and actions that elevate and honor these pandemic counterstories with the attention and audience they deserve. The ultimate goal is for society to recognize counter-stories no longer as counter to the prevailing narrative, but rather as enriching dimensions of our shared reality. Elevating these stories allows us to bear witness to our diverse collective experiences, expose our complacency, and enable us to confront power and privilege in the process.

So, who will be the storytellers recounting the history of the COVID-19 pandemic? Our hope is all of us will.

Acknowledgements: The authors would like to acknowledge the mentorship and expertise of Dr. Tonya Kneff-Chang and Dr. Karri Grob as well as editing support from Linda Camaj Deda and Samuel Schotland.

Corresponding Author: Ruth Bishop, MBA; University of Michigan Medical School, 1301 Catherine St, Ann Arbor, MI 48109, USA (e-mail: ruthbi@umich.edu).

\section{Declarations:}

Conflict of Interest: The authors declare that they do not have a conflict of interest.

\section{REFERENCES}

1. Solórzano DG, Yosso TJ. Critical Race Methodology: Counter-Storytelling as an Analytical Framework for Education Research. Qual Inq. 2002;8(1):23-44. doi:https://doi.org/10.1177/107780040200800103

2. Delgado R. Storytelling for Oppositionists and Others: A Plea for Narrative. Mich Law Rev. 1989;87(8):2411-2441. doi:https://doi.org/10.2307/ 1289308

3. Kantamneni N. The impact of the COVID-19 pandemic on marginalized populations in the United States: A research agenda. $J$ Vocat Behav. 2020;119:103439. doi:https://doi.org/10.1016/j.jvb.2020.103439

4. Byrd WM, Clayton LA. Race, medicine, and health care in the United States: a historical survey. J Natl Med Assoc. 2001;93(3 Suppl): 11S-34S.

5. Washington HA. Medical Apartheid: The Dark History of Medical Experi mentation on Black Americans from Colonial Times to the Present. Doubleday; 2006.

6. Purkey E, MacKenzie M. Experience of healthcare among the homeless and vulnerably housed a qualitative study: opportunities for equityoriented health care. Int $J$ Equity Health. 2019;18(1):101. doi:https://doi. org/10.1186/s12939-019-1004-4

7. Nuriddin A. Psychiatric Jim Crow: Desegregation at the Crownsville State Hospital, 1948-1970. J Hist Med Allied Sci. 2019;74(1):85-106. doi:https://doi.org/10.1093/jhmas/jry025

Publisher's Note: Springer Nature remains neutral with regard to jurisdictional claims in published maps and institutional affiliations. 